\title{
Histomorphological evaluation of osteoclast cell count in femur bone of mice induced by anastrazole and protective effect of olive oil.
}

\footnotetext{
1. M.Phil (Histopathology)

Lecturer Pathology

Khyber Girls Medical College Peshawar.

2. M.Phil (Histopathology) Assistant Professor Pathology Khyber Girls Medical College Peshawar.

3. FCPS (Histopathology) Lecturer Pathology Khyber Girls Medical College Peshawar.

4. M.Phil (Pharmacology) Assistant Professor Kabeer Medical Medical College Peshawar.

5. M.Phil (Histopathology) Professor Pathology Khyber Girls Medical College Peshawar

6. M.Phil (Chemical Pathology) Assistant Professor Pathology Khyber Girls Medical College Peshawar.
}

Correspondence Address:

Dr. Anjum Ishaque

Department Pathology

Khyber Girls Medical College

Peshawar.

anjumshakeel1970@gmail.com

Article received on:

08/02/2021

Accepted for publication:

$07 / 05 / 2021$
Anjum Ishaque ${ }^{1}$, Saima Nadeem², Shagufta Nisar ${ }^{3}$, Hasnain Ali Shah", Khalid Javed ${ }^{5}$, Munir Hussain ${ }^{6}$

ABSTRACT... Objective: The objective of this study is to find out protective effect of olive oil to prevent bone loss by decreasing osteoclast count in patient receiving Anastrazole. Study Design: Experimental study. Setting: Pakistan Council for Scientific and Industrial Research (PCSIR) Animal House, Peshawar and Pathology Lab KGMC Peshawar. Period: March 2019 to December 2019. Material \& Methods: Sixty female albino mice 6-8 weeks of age were selected for this experimental study and Aromatase inhibitor drug Anastrazole was given alone and in combination with olive oil once daily for 30 successive days. Femur bone samples were collected and stained with Eosin and Hematoxylin for histomorphological evaluation of osteoclast cell count in three all three groups i.e. control group, those receiving Anastrazole alone and those given Anastrazole and olive oil in combination. Results: The mean weight of all experimental female albino mice before study was 30.77-33.05 grams and after the study was 30.84- 21.31 grams. Control group 1 which was given normal diet showed increased weight of mice with less osteoclast cell count as compared to experimental groups (2 and 3). In group 2 (Drugged) which was given Anastrazole, weight of were lesser than control group 1 and group 3(Anastrazole + olive oil), while, osteoclast score was greater than group 1 (control) and group 3 (Anastrazole + olive oil). Group3 (Drugged+ Olive oil) showed greater weight of mice than group 2 (Anastrazole) but, lesser than control group 1. Osteoclast score was greater than control group but lesser than group 2 (Anastrazole). Conclusion: The results showed positive and protective effects of olive oil against Anastrazole induced bone loss in female albino mice.

Key words: $\quad$ Aromatase Inhibitor, Breast Cancer, BMD, Chemotherapy Osteoporosis, Olive Oil.

Article Citation: Ishaque A, Nadeem S, Nisar S, Shah HA, Javed K, Hussain M. Histomorphological evaluation of osteoclast cell count in femur bone of mice induced by anastrazole and protective effect of olive oil. Professional Med $\mathrm{J}$ 2021; 28(12):1837-1843. https://doi.org/10.29309/TPMJ/2021.28.12.6413

\section{INTRODUCTION}

Cancer is one of a prominent cause of mortality worldwide. As population grows, the overall number of cases of cancer and mortality increases. ${ }^{1}$ Cancer generally develops when there are changes in the DNA of the cell, interfering with the orderly process of cell growth. These cells with altered DNA start growing abnormally and uncontrollably, forming a mass called tumor. ${ }^{2}$

Cancer of breast is consistently detected and diagnosed and the majority of the women receiving treatment will be healed. Breast cancer is heterogeneous class of tumors, different in their presentation as well as in their response to treatment. ${ }^{3,4}$
CA breast is classified into three main types, on the basis of occurrence or lack of molecular markers for hormonal receptors (estrogens or progesterone receptors) and for human epidermal growth factor 2 (ERBB2; formerly HER2):

1. HR+ (Hormone receptor positive) /ERBB2 negative ( $70 \%$ of patients).

$2.15 \%-20 \%$ of ERBB2 positive/hormone receptor negative and

3. $15 \%$ of Triple-negative tumors (absent all 3 typical and classic molecular markers of tumor. ${ }^{5,6}$

Most of the breast cancer cases (90\%) are not metastatic atthetime of diagnosis. ${ }^{6}$ As compared to the other two subtypes, the chances of recurrence 
are more in triple-negative breast cancer. There is $85 \%$ of 5 -year survival rate for triple-negative breast tumors (stage 1) as compared to $94-99 \%$ for other 2 types of breast cancers $(\mathrm{HR}+$ and ERBB2 +) Breast cancer therapies are usually administered, in the adjuvant setting, with aim and determination of curing the disease. Nearly $70 \%$ of breast tumors possess the hormone receptors (oestrogen or progesterone), therefore in order to reduce the risk of relapse, antihormonal treatments are frequently used. ${ }^{7}$ In patients of early stage breast cancer, receiving anticancer therapy, there is an amplified osteoporosis risk. Chemotherapy and anti-estrogens drugs induced amenorrhoea, triggers bone loss. Hence, in such patients, the management of bone health is an important factor of care and survival. , $^{5,8}$

Anti-hormonal therapies and chemotherapy used in breast cancer treatment can have a harmful destructive influence on bone health. Patients 50 years of age or older, reduced bone mass are a major public health hazard. Almost 45\% of patients above 50 years of age have either osteopenia or osteoporosis as outlined by WHO [World Health Organization]..$^{10,11}$

The overall yearly incidence of osteoporotic fractures is bigger compared to CA breast, cardiac arrest and stroke combined. OP (Osteoporosis) is held accountable in nearly three million fractures around the world, at yearly expenditure of $\$ 25.3$ billion. ${ }^{12}$

Aromatase inhibitors (Al) like Anastrazole and letrozole are endocrine drugs used in patients of breast cancer and they exert their action by blocking the production of estrogen. ${ }^{13}$ Estrogen performs a dynamic function in growth and development of bone along with the supervision of adult bone turnover both in men and women. ${ }^{14}$ Estrogen also prevents osteoclasts (bone resorption cells) directly and promotes its apoptosis thus inhibiting bone resorption. Clear impacts of estrogen on osteocytes, osteoblasts and osteoclasts, lead to inhibition of bone remodelling, maintenance of bone development and decreased bone resorption respectively. ${ }^{15}$ Osteoporosis is dysregulation of bone remodelling, where the resorption of bones is higher than that of formation, causing net bone loss. ${ }^{16}$ The root cause of osteoporosis is the deficiency of sex hormone mainly estrogen.

Olive oil and its phenolic compounds, both in vivo and in vitro have antioxidant properties. ${ }^{17,18}$ The consumption of phenols may prevent bone cells damage caused by oxidation and has positive impact on BMD.Moreover; the bone remodeling procedure confirms the principle that inflammation has significant contribution in the pathogenesis of osteoporosis. Standard inflammatory markers were found to be higher among subjects experiencing an episode of fracture. ${ }^{19}$ It was proposed that phenolic compounds give the required health benefits due to their impact on bone cell metabolism. ${ }^{20}$ Olive oil was discovered to promote bone health by facilitating osteoblasts development from bone marrow stem cells, suggesting that its intake may have preventive effect on osteoporosis. ${ }^{21}$

\section{MATERIAL \& METHODS}

The study proposal was accepted by the ASRB (Advanced Study and Research Board) under DIR/ KMU AS\&RB/EM/000892 and the KGMC Ethical Board, after approved by the Graduate Study committee (GSC) KGMC.

This experimental study was conducted in "Pakistan Council for Scientific and Industrial Research (PCSIR) animal house, Peshawar and Pathology lab KGMC Peshawar. It took 9 months to complete the research work (March 2019 to December 2019).

It includes sixty female albino mice, bought from National Institute of Health Islamabad, according to the inclusion criteria i.e.6-8 week's old healthy female albino mice having weight of 20-40 grams. Total 60 female albino mice were included in this study. They were studied for the adverse effects of drug Anastrazole and protective effects of Olive oil given orally. Then, histomorphological assessment was done on femur bone specimens of albino mice (female) to estimate the efficacy of olive oil versus the toxicity of Anastrazole. 
Sixty female albino mice were segregated into 3 separate groups.

Group 1 the control group which comprises of total of 10 mice. Mice in this group were on routine standard diet only.

Group 2 had 25 albino mice and were on drug Anastrazole, with the dose of $0.1 \mathrm{mg} / \mathrm{kg}$ body weight once daily.

Group 3 had 25 female albino mice that were given $1 \mathrm{ml}$ olive oil daily along with $0.1 \mathrm{mg} / \mathrm{kg} / \mathrm{per}$ day of Anastrazole drug.

All mice were kept in individual cages by groups, in animal house of PCSIR, Peshawar, under normal standard environmental condition i.e.12 hour's period of light and 12 hour's period of dark. Normal standard food and water was supplied according to the standard protocol.

\section{Collection of femur bone for osteoclast cell count}

All the animals of intervention groups (1, 2 \& 3 ), were under observation for 30 days. Group 2 received drug Anastrazole $(0.1 \mathrm{mg} / \mathrm{kg} /$ day) and Group 3 received $1 \mathrm{ml}$ olive oil in addition to $0.1 \mathrm{mg} / \mathrm{ml} /$ day of Anastrazole for full duration of 30 days. On day $31^{\text {st }}$, all animals were sacrificed and dissected on dissection board. A straight incision was given in the middle of each limb just right to the lower abdomen. The femur was exposed by removing muscle (hamstring) away. Then, femur was held in forceps and femur head was freed from acetabulum and pulled away from tibia and knee joint.

\section{Femur Bones Preservation}

All the femur bones were washed and then preserved in $10 \%$ formalin in separate jars. All the slaughtered mice were then disposed of, keeping in view the guidelines of animal's laboratory science. The reagents used in the study, were carefully selected according to price, availability and performance. All the reagents were already in use for purposes like preservation, dehydration, clearing, fixation and staining etc, in the Pathology laboratory of KGMC.

\section{Quantitative Parameters}

The experimental female albino mice, treated with Anastrazole and Anastrazole and olive oil were matched in terms of various quantitative parameters like weight and Osteoclasts number. Osteoclasts cells were measured from the HE stained, prepared slides of the femur bone of all the three experimental groups:

SCORE 0: Normal (almost no osteoclasts)

SCORE 1: few osteoclast numbers (lining < than $5 \%$ of most affected bone surface)

SCORE 2: Some osteoclasts (lining 5-25\% of most affected bone surface)

SCRORE 3: Many osteoclasts (lining $25-50 \%$ of most affected bone surface)

SCORE 4: Numerous osteoclasts (lining $>50 \%$ of most affected bone surface). ${ }^{22}$

Data was entered and analysed using SPSS version 23. Means and standard deviations were calculated for weight and osteoclasts numbers. The means of different variables of all three groups were compared to get the level of significance by applying one way Anova. A level of $\leq .05$ at $95 \%$ confidence interval was taken as significant.

\section{RESULTS}

This experimental research was conducted in female albino mice, to observe and study the outcomes of anticancer drug Anastrazole given alone and also in combination with olive oil. The findings obtained from this research showed the consequences of Anastrazole alone and Anastrazole along with olive oil on the femur bone of mice from various aspects. For this very purpose microscopic examination on the prepared slides obtained from the femur bone of experimental mice, was performed.

A total of 5 mice were found dead at different days in both group 2 and 3 during the course of study, 20 mice were remaining in each group 2 and 3 . So, total number of mice was 50 at the end of our study. All remaining 50 female albino mice included in this research were of same age (6-8 weeks), healthy and active. They were categorized into 3 groups.10 mice included in control group (group 1), were active, healthy and 
brisk in their respond to external stimuli. The 20 mice of group 2 (given Anastrazole alone) were found less active, weak and showed almost negligible response to stimuli at the end of study. While the 20mice of group 3 (Anastrazole and olive oil group) were noticed to be more active, healthier and good in their response to external stimuli than mice of group 2 but less than group-1. General observations of gross features of experimental mice such as general health or physique, activity level, their response to stimuli, both at the start and end of study. Weight of mice of all experimental groups, at the start and after the end of experiment.

\section{Weight of Mice of All 3 Groups, Before and After the Research}

The mean weight in gram of all experimental mice before and after experimental are shown in Table-I and II respectively.

\begin{tabular}{|l|c|c|c|}
\hline \multicolumn{1}{|c|}{ Groups } & Number & Mean & $\begin{array}{c}\text { Std. } \\
\text { Deviation }\end{array}$ \\
\hline 1. Control & 10 & $30.77 \mathrm{mg}$ & 1.15 \\
\hline 2. Drugged mice & 20 & $32.68 \mathrm{mg}$ & 1.831 \\
\hline 3. Drugged and Olive oil & 20 & $33.05 \mathrm{mg}$ & 2.408 \\
\hline
\end{tabular}

Table-I. Weight of mice before experiment.

\begin{tabular}{|l|c|c|c|c|}
\hline \multicolumn{1}{|c|}{ Groups } & Number & Mean & $\begin{array}{c}\text { Std. } \\
\text { Deviation }\end{array}$ & P-Value \\
\hline 1. Control & 10 & $30.84 \mathrm{mg}$ & 1.30 & \\
\hline 2. Drugged mice & 20 & $17.11 \mathrm{mg}$ & 1.83 & \multirow{2}{*}{$<.001$} \\
\hline \begin{tabular}{l|l|l|} 
3. Drugged and \\
Olive oil
\end{tabular} & 20 & $21.31 \mathrm{mg}$ & 2.20 & \\
\hline
\end{tabular}

Table-II. Weight of mice after experiment.

On applying one way ANOVA a highly significant difference $(<.001)$ among all the groups was found. The mean weight of the group 3 mice $(21.31 \pm 2.20)$ was significantly higher than those of group $2(17.11 \pm 1.83)$.

HE stained slides of mice femur bone of all three groups were examined under the microscope for Osteoclast count.

The overall mean of osteoclast cells count of all three groups $(1,2$, and 3 ) is shown in table 3 .
The difference is highly statistical among all three groups i.e. p-value, rejecting the null hypothesis.

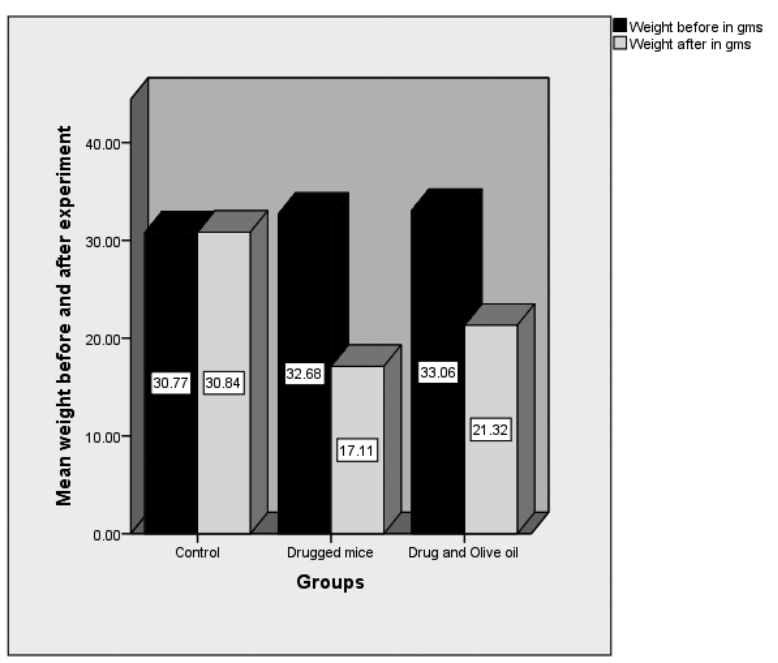

Figure-1. Comparison of mean weight of all mice groups.

\begin{tabular}{|l|c|}
\hline \multicolumn{1}{|c|}{ Groups } & Osteoclast Cell Count \\
\hline Control & $0-1$ \\
\hline 1. Anastrazole & $1-4$ mostly 4 \\
\hline 2. Anastrazole + Olive Oil & $1-2$ \\
\hline
\end{tabular}

Table-III. Score of osteoclast cells count according to Lewis criteria.

\begin{tabular}{|l|c|c|c|c|}
\hline Groups & Number & $\begin{array}{c}\text { Osteoclast } \\
\text { Score }\end{array}$ & $\begin{array}{c}\text { St. } \\
\text { deviation }\end{array}$ & $\begin{array}{c}\text { P- } \\
\text { Value }\end{array}$ \\
\hline Control & 10 & .70 & .67495 & \\
\cline { 1 - 3 } $\begin{array}{l}\text { Drugged } \\
\text { mice }\end{array}$ & 20 & 8.35 & 1.26803 & \multirow{2}{*}{$<.001$} \\
\cline { 1 - 3 } $\begin{array}{l}\text { Drug and } \\
\text { Olive oil }\end{array}$ & 20 & 4.45 & .94451 & \\
\cline { 1 - 2 } & & &
\end{tabular}

Table-IV. Comparison of osteoclast score in all mice groups.

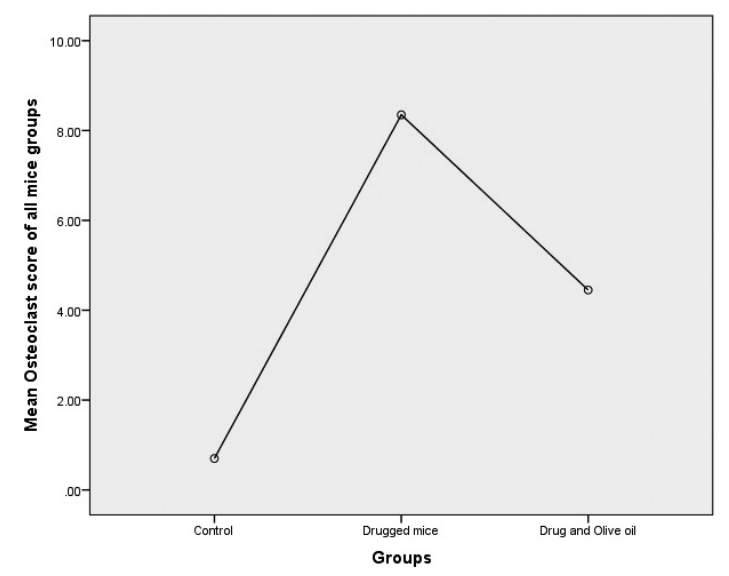

Figure-2. Mean plot showing comparison of osteoclast score in all groups. 

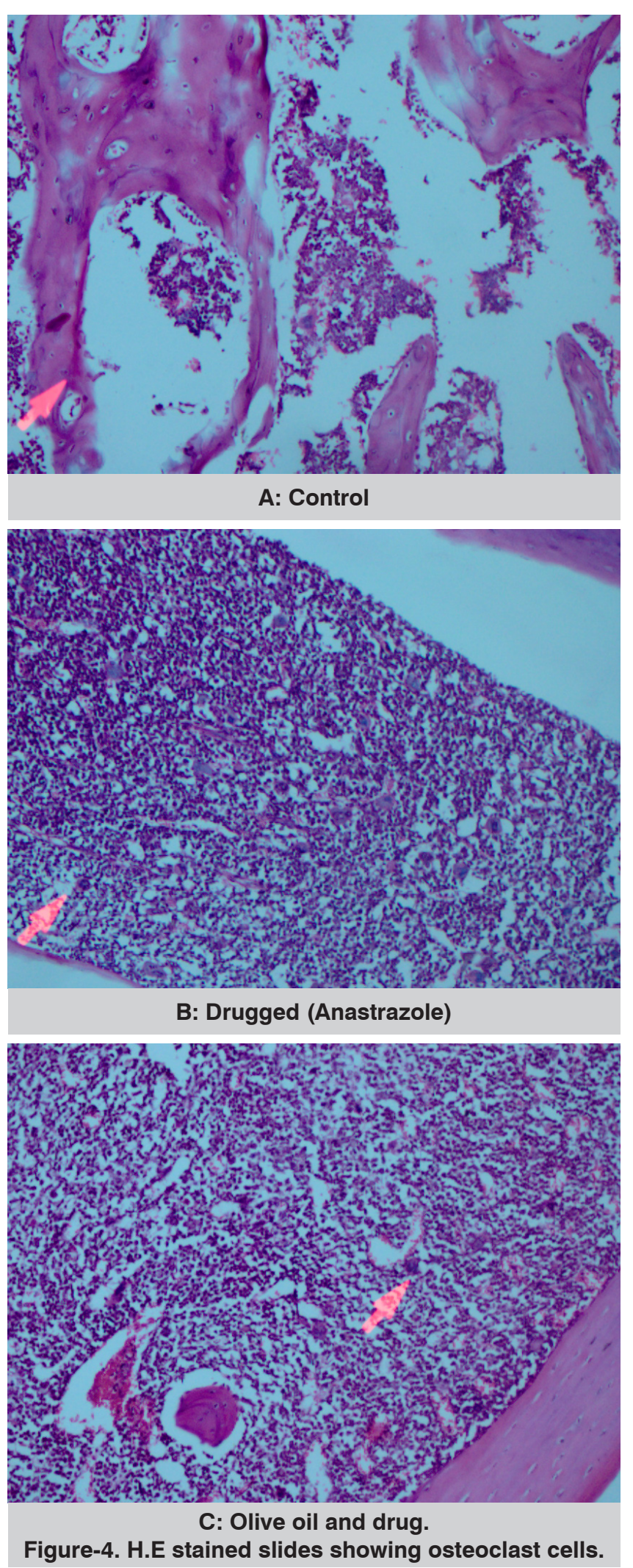

\section{DISCUSSION}

The main objective of this experimental study was to evaluate the impact of the anticancer drug Anastrazole on bones, commonly prescribed in postmenopausal, hormone sensitive $(\mathrm{HR}+)$ breast cancer patients. Whereas, the efficacy and effectiveness of olive oil on bone mineral density (BMD) was also observed.

Our study also showed increased osteoclast score / number associated with group 2 (Anastrazole) and group 3 (Anastrazole and olive oil), as compared to group1 (control). The osteoclast score was highest in Anastrazole treated group (2) among the 3 experimental groups.

This was also proved by another study conducted on rats, showing highly significant $(P<0.05)$ osteoclast activity and number in Anastrazole group. This effect was attributed to decreased estrogen level causing osteoclast activation leading to enhanced osteoporotic risk. ${ }^{23}$

Aromatase inhibitors like Anastrazole cause increased bone turnover by significantly reducing BMD and amplify the risk of fractures in women especially post-menopausal with breast cancer. ${ }^{24}$

Consuming olive oil has been shown to mend bone health. Studies done on animals, revealed that diet containing olives, and olive oil improve skeletal health by improving bone mineral density, bone strength in ovariectomized rats. This could be due to ability of olive oil in reducing oxidative stress and inflammation. Olive oil also enhances proliferation of pre-osteoblasts, differentiation of osteoblasts and decreases the formation of osteoclast-like cells. Human studies discovered that daily intake of olive oil could inhibit bone mineral density loss and reduces the risk of fracture..$^{25}$

\section{CONCLUSION}

Our experimental trail showed that, Aromatase inhibitor drugs like Anastrazole caused marked reduction of serum estrogen levels in the female albino mice which led to increase the number of osteoclasts denoting the enhancement of osteoporotic process in the femur bones of female albino mice. 
However, the combination of Anastrazole and olive oil had beneficial as well as protective effects in decreasing the osteoclast's count of femur bones. Thus the study shows protective effects of olive oil on bone mineral density, reducing the osteoporotic changes and lowering the risk of future fractures.

\section{RECOMMENDATIONS}

a. More such studies should be conducted to emphasize the fact that olive oil should be given as an adjuvant to the patients receiving Aromatase inhibitors instead of drugs to prevent osteoporosis as they are associated with side effects and they are not cost effective.

b. As addition of olive oil imparts protection against osteoporosis, so it is recommended that olive oil should be a part of daily routine diet like Mediterranean diet in order to lower the risk of future fractures especially in postmenopausal females.

\section{Copyright@ 07 May, 2021.}

\section{REFERENCES}

1. Torre LA, Siegel RL, Ward EM, Jemal A. Global cancer incidence and mortality rates and trends-an update. Cancer Epidemiology and Prevention Biomarkers. 2016; 25(1):16-27.

2. Bodai BI, Tuso P. Breast cancer survivorship: A comprehensive review of long-term medical issues and lifestyle recommendations. The Permanente Journal. 2015; 19(2):48-79.

3. Li C, Uribe D, Daling J. Clinical characteristics of different histologic types of breast cancer. British journal of cancer. 2005; 93(9):1046.

4. Rosa M. Advances in the molecular analysis of breast cancer: Pathway toward personalized medicine. Cancer Control. 2015; 22(2):211-9.

5. Costa T. PAK4 signaling in development and cancer. KI open Archive. 2019.

6. Waks AG, Winer EP. Breast cancer treatment: A review. Jama. 2019; 321(3):288-300.

7. Burstein HJ, Griggs JJ, Prestrud AA, Temin S. American society of clinical oncology clinical practice guideline update on adjuvant endocrine therapy for women with hormone receptor-positive breast cancer. Journal of oncology practice. 2010; 6(5):243-6.
8. Shah R, Rosso K, Nathanson SD. Pathogenesis, prevention, diagnosis and treatment of breast cancer. World journal of clinical oncology. 2014; 5(3):283.

9. Zhang B-N, Cao X-C, Chen J-Y, Chen J, Fu L, Hu X-C, et al. Guidelines on the diagnosis and treatment of breast cancer (2011 edition). Gland surgery. 2012; $1(1): 39$.

10. Kanis JA, Melton III LJ, Christiansen C, Johnston CC, Khaltaev N. The diagnosis of osteoporosis. Journal of bone and mineral research. 1994; 9(8):1137-41.

11. Siris E, Brenneman S, Barrett-Connor E, Miller P, Sajjan $\mathrm{S}$, Berger $\mathrm{M}$, et al. The effect of age and bone mineral density on the absolute, excess, and relative risk of fracture in postmenopausal women aged 5099: results from the National Osteoporosis Risk Assessment (NORA). Osteoporosis international. 2006; 17(4):565-74.

12. Coleman RE, Banks LM, Girgis SI, Kilburn LS, Vrdoljak $E$, Fox J, et al. Skeletal effects of exemestane on bone-mineral density, bone biomarkers, and fracture incidence in postmenopausal women with early breast cancer participating in the Intergroup Exemestane Study (IES): A randomised controlled study. The lancet oncology. 2007; 8(2):119-27.

13. Boutas I, Pergialiotis V, Salakos N, Agrogiannis G, Konstantopoulos P, Korou L-M, et al. The impact of Anastrazole and Letrozole on the metabolic profile in an experimental animal model. Scientific reports. 2015; 5:17493.

14. Khosla S, Melton III LJ, Riggs BL. The unitary model for estrogen deficiency and the pathogenesis of osteoporosis: Is a revision needed? Journal of bone and mineral research. $2011 ; 26(3): 441-51$.

15. Khosla S, Oursler MJ, Monroe DG. Estrogen and the skeleton. Trends in Endocrinology \& Metabolism. 2012;23(11):576-81.

16. Feng X, McDonald JM. Disorders of bone remodeling. Annual Review of Pathology: Mechanisms of Disease. 2011;6:121-45.

17. Cicerale S, Lucas L, Keast R. Antimicrobial, antioxidant and anti-inflammatory phenolic activities in extra virgin olive oil. Current opinion in biotechnology. 2012; 23(2):129-35.

18. Oliveras-López M-J, Molina JJM, Mir MV, Rey EF, Martín F, de la Serrana HL-G. Extra virgin olive oil (EVOO) consumption and antioxidant status in healthy institutionalized elderly humans. Archives of gerontology and geriatrics. 2013; 57(2):234-42. 
19. Cauley JA, Danielson ME, Boudreau RM, Forrest KY, Zmuda JM, Pahor M, et al. Inflammatory markers and incident fracture risk in older men and women: The Health Aging and Body Composition Study. Journal of bone and mineral research. 2007; 22(7):1088-95.

20. Trzeciakiewicz A, Habauzit V, Horcajada M-N. When nutrition interacts with osteoblast function: molecular mechanisms of polyphenols. Nutrition Research Reviews. 2009; 22(1):68-81.

21. Garcia-Martinez O, Rivas A, Ramos-Torrecillas J, De Luna-Bertos E, Ruiz C. The effect of olive oil on osteoporosis prevention. International journal of food sciences and nutrition. 2014; 65(7):834-40.

22. Bolon B, Morony S, Cheng $\mathrm{Y}, \mathrm{Hu} \mathrm{Y}-\mathrm{L}$, Feige $\mathrm{U}$. Osteoclast numbers in Lewis rats with adjuvantinduced arthritis: identification of preferred sites and parameters for rapid quantitative analysis. Veterinary pathology. 2004; 41(1):30-6.
23. Abdulhadi $\mathrm{Y}$, Ahmed J. The role of genistein and fish oil in molecular and biochemical disorders of osteoclastogenesis as a risk factor for osteoporosis induced by anastrozole in laboratory rats (Rattus norvegicus). Basrah Journal of Veterinary Research. 2019; 18:208-23.

24. Folkestad L, Bjarnason NH, Bjerregaard JK, Brixen K. The effect of aromatase inhibitors on bone metabolism. Basic \& clinical pharmacology \& toxicology. 2009; 104(1):3-10.

25. Chin K-Y, Ima-Nirwana S. Olives and bone: A green osteoporosis prevention option. International journal of environmental research and public health. 2016; 13(8):755.

\begin{tabular}{|c|l|l|l|}
\hline \multicolumn{3}{|c|}{ AUTHORSHIP AND CONTRIBUTION DECLARATION } \\
\hline No. & Author(s) Full Name & \multicolumn{1}{|c|}{ Contribution to the paper } & Author(s) Signature \\
\hline 1 & Anjum Ishaque & $\begin{array}{l}\text { Conception, synthesis \& } \\
\text { planning. } \\
\text { Conception, synthesis \& } \\
\text { planning. } \\
\text { Discussion and review. }\end{array}$ \\
\hline 3 & Saima Nadeem & Shagufta Nisar & Data interpretation and review. \\
\hline 5 & Khalid Javed & Munir Hussain & $\begin{array}{l}\text { Conception, analysis and } \\
\text { review. } \\
\text { Results, Methodology and } \\
\text { analysis, Data interpretation. }\end{array}$ \\
\hline
\end{tabular}

